Markus V. Nahas ${ }^{1}$

Fabiana Maluf Rabacow ${ }^{1}$

Silvia do Valle Pereira ${ }^{2}$

Adriano Ferreti Borgatto ${ }^{1}$

\section{Reprodutibilidade de uma escala para avaliar a percepção dos trabalhadores quanto ao ambiente e às condições de trabalho}

\author{
Test and retest reliability of a scale to measure workers' perception \\ of work environment and working conditions
}

\author{
${ }^{1}$ Núcleo de Pesquisa em Atividade \\ Física e Saúde - NuPAF, Universidade \\ Federal de Santa Catarina - UFSC \\ ${ }^{2}$ Consultoria em Responsabilidade Cor- \\ porativa - Serviço Social da Indústria \\ - SESI-SC \\ Contato: \\ Markus V. Nahas \\ Universidade Federal de Santa Catarina \\ / Centro de Desportos \\ Campus Universitário - Trindade, \\ Florianópolis, SC \\ CEP: $88.040-900$ \\ E-mail: \\ markus@cds.ufsc.br
}

Recebido: 08/05/2009

Revisado: 17/07/2009

Aprovado: 21/08/2009

\section{Resumo}

Objetivo: Apresentar as características gerais e avaliar a reprodutibilidade da escala Perfil do ambiente e condições de trabalho. Método: A escala foi submetida à validação de face e de conteúdo por três especialistas, além de aplicação piloto. Responderam ao instrumento, em duas ocasiões, com intervalo de uma semana, 122 trabalhadores da indústria, de ambos os sexos e diferentes graus de escolaridade. A média de idade foi de 29 anos (DP=8,44). A escala foi estruturada com cinco componentes principais, cada um com três itens. Utilizou-se o Coeficiente Kappa para comparações das frequências de respostas nas duas aplicações, de forma global e para cada um dos cinco componentes da escala. Resultados: A análise global resultou no coeficiente igual a 0,64, com 77,6\% de concordância das respostas (valor considerado substancial). Conclusão: A escala proposta foi estruturada a partir das evidências da literatura e análise de especialistas, sendo de fácil compreensão e aplicação rápida. O teste de reprodutibilidade da escala para avaliação do perfil do ambiente e das condições de trabalho mostrou níveis de concordância substanciais, portanto, aceitáveis para reprodutibilidade, justificando sua aplicação em estudos que envolvam trabalhadores da indústria, de ambos os sexos e diversas funções, mas com escolaridade superior ao Ensino Fundamental.

Palavras-chave: trabalhadores, escalas, ambiente de trabalho, condições de trabalho.

\begin{abstract}
Objective: To introduce the scale Profile of Work Environment and Working Conditions and assess its degree of test-retest reliability. Methods: The scale was submitted to three experts for face and content validity, and pilot-tested with a group of industry workers. For reliability analysis, the instrument was applied twice, one week apart, to 122 industrial workers, males and females, with different educational backgrounds. Average age was 29 years ( $S D=8.44)$. The scale included five components, with three items in each one. The Kappa coefficient was utilized to compare test and re-test agreement, both globally and for each component of the scale. Results: Kappa coefficient for the entire scale was 0.64 , with $77.6 \%$ agreement between applications. Conclusion: the scale was structured following evidences from the literature and experts' analyses, being easy to respond by workers, in a short period of time. The reliability coefficients of the scale indicated that the test has good (substantial) level of reprodutibility when applied to workers of both sexes, and diverse types of jobs, but with educational level above elementary school.
\end{abstract}

Keywords: workers, scales, work environment, working conditions. 


\section{Introdução}

O conceito de qualidade de vida e, em particular, de qualidade de vida do trabalhador (QVT) vem ganhando destaque, tanto no meio acadêmico, quanto empresarial, por seu valor em todos os segmentos da sociedade. A ideia de que se pode derivar alguma satisfação e felicidade do trabalho é uma concepção recente, visto que, historicamente, trabalho era sinônimo de sacrifício, quando não, de castigo.

Do trabalho escravo, passando pela revolução industrial, até a era da tecnologia e da informática, chegou-se ao mundo contemporâneo do trabalho, com mudanças significativas nas demandas sobre o organismo humano. Do desgaste essencialmente físico, decorrente das pesadas cargas de trabalho e das longas jornadas em ambiente muitas vezes insalubre, chegou-se a uma configuração de trabalho com pouca demanda física, mas reconhecida como mental e espiritualmente pouco saudável. Este formato predominante do trabalho no mundo atual, com grande competitividade e enorme demanda psicossocial, vem instigando estudos de diferentes áreas do conhecimento (ASSUNÇÃO, 2003; VASCONCELOS, 2001).

Há uma tendência de se buscar a adequação dos ambientes e das condições de trabalho ao ser humano de forma a garantir tanto a sustentabilidade econômica quanto o bem-estar e a qualidade de vida (PEREIRA, 2001; VILARTA; GONÇALVES, 2004; METZNER; FISCHER, 2001; KERN, 1997). Há muitas evidências de que o ambiente e as condições de trabalho (além dos estilos de vida) têm grande influência na saúde e na qualidade de vida de todos os indivíduos. Expressões como satisfação no trabalho, salário adequado, sucesso na carreira, bens adquiridos, relações sociais, disposição, entre outras, têm sido cada vez mais associadas ao conceito de qualidade de vida, pois grande parte de nossa vida acontece no ambiente de trabalho (SUCESSO, 1998).

No contexto de vida atual, fatores socioambientais (o ambiente e as condições de trabalho, no caso do indivíduo trabalhador) somados a fatores individuais (estilo de vida) resultam na percepção do bem-estar geral do indivíduo, o que reflete a sua qualidade de vida.

Mesmo com algumas limitações, o uso de questionários e escalas para avaliar constructos como a qualidade de vida tem predominado por sua simplicidade, de baixo custo e abrangência (THOMAS; NELSON, 2002). As principais limitações estão na imprecisão das respostas e na falta de um processo de construção e validação adequados (BARROS; NAHAS, 2000). Características psicométricas dos instrumentos, como a validade e a reprodutibilidade, devem ser consideradas quando se deseja medir qualquer variável.

Este trabalho tem por objetivo apresentar as características gerais e o grau de reprodutibilidade de um instrumento denominado Perfil do ambiente e condições de trabalho, desenvolvido para adultos trabalhadores. Esta escala, acompanhada de um registro pictorial dos resultados, pode servir como um instrumento educacional e motivacional a ser utilizado com adultos trabalhadores $^{1}$. O constructo "ambiente e condições de trabalho", que se pretende avaliar com a escala, serve, também, como uma das dimensões no modelo de qualidade de vida do trabalhador, proposto por Nahas (2006, p. 14).

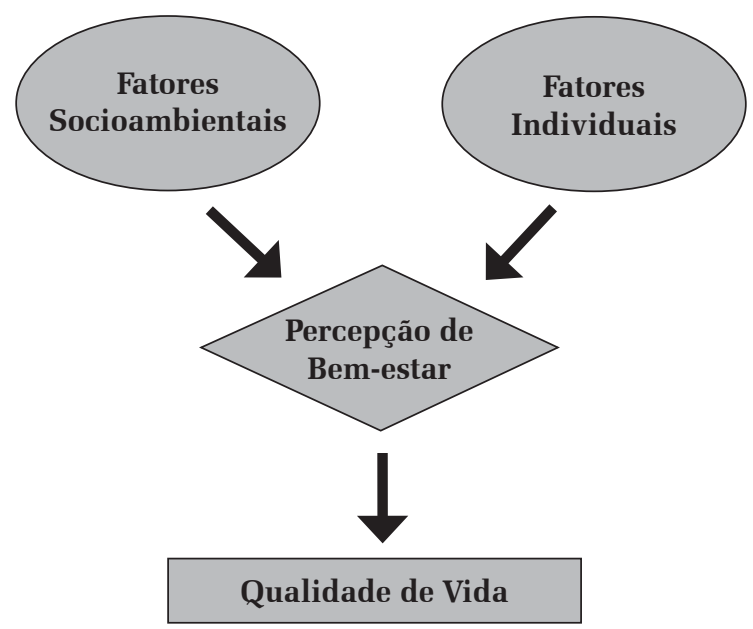

Figura 1 Qualidade de vida: um modelo conceitual (NAHAS, 2006, p. 14)

${ }^{1}$ Disponível em: www.nupaf.ufsc.br 


\section{Métodos}

\section{Amostra}

A amostra foi composta por 122 trabalhadores da indústria catarinense, selecionados por conveniência em diferentes empresas, de ambos os sexos, com idade média de 29 anos ( $\mathrm{DP}=8,44$ anos), em diferentes funções e com diferentes graus de escolaridade.

\section{Características da escala}

Uma versão preliminar do instrumento Perfil do ambiente e condições de trabalho foi utilizada inicialmente por Pereira (2001). A escala foi submetida à validação de face e conteúdo por três especialistas da área (professores doutores da UFSC). Além disso, foi realizada uma aplicação piloto com trabalhadores da indústria, o que serviu para observações quanto à pertinência dos itens, ao grau de dificuldade e ao tempo necessário para responder.

A estrutura da escala (cinco componentes principais, com três itens em cada componente) tem como base o modelo teórico do Pentáculo do bem-estar (NAHAS; BARROS; FRANCALACCI, 2000) e o instrumento derivado deste modelo que avalia o Perfil do estilo de vida (NAHAS, 2006). Este instrumento mostrou boa reprodutibilidade, com coeficiente de concordân- cia entre duas medidas realizadas, variando entre 74\% e 93\% nos diversos componentes (BOTH et al., 2008).

Considerando as informações da literatura corrente e a opinião de especialistas, os cinco componentes escolhidos como indicadores socioambientais, relacionados à qualidade de vida do trabalhador, foram: ambiente físico, ambiente social, desenvolvimento e realização profissional, remuneração e benefícios e relevância social do trabalho. Cada componente é composto por três itens, com respostas numa escala Likert de zero a três, sendo que: 0 corresponde à condição ruim; 1 , regular; 2 , boa; e 3, excelente (Quadro 1).

\section{Análise dos dados}

Para verificar o grau de concordância entre a primeira e a segunda aplicação (com uma semana de intervalo), utilizou-se o índice de concordância Kappa através do programa SAS (versão 8.02). De acordo com o critério de Landis e Koch (1997), os valores do coeficiente de Kappa maiores do que 0,80 representam concordância "quase perfeita"; entre 0,60 e 0,80, "substancial"; entre 0,40 e 0,60, "moderada"; e abaixo de 0,40 representam concordância "fraca".

Foram realizadas comparações das frequências de respostas nas duas aplicações para cada um dos cinco componentes da escala, considerando-se os diversos agrupamentos na amostra (sexo, função e escolaridade).

Quadro 1 Componentes principais e itens da escala Perfil do ambiente e condições de trabalho

\begin{tabular}{|c|c|}
\hline Componente & Itens \\
\hline \multirow{3}{*}{ Ambiente físico } & Condições de limpeza e iluminação do local de trabalho \\
\hline & Adequação ergonômica do mobiliário e dos equipamentos \\
\hline & Condições de ruído e temperatura \\
\hline \multirow{3}{*}{ Ambiente social } & Relacionamento com os demais trabalhadores \\
\hline & Relacionamento com o(s) chefe(s) imediato(s) \\
\hline & $\begin{array}{l}\text { Oportunidades para expressar opiniões relacionadas ao } \\
\text { trabalho }\end{array}$ \\
\hline \multirow{3}{*}{$\begin{array}{l}\text { Desenvolvimento e realiza- } \\
\text { ção profissional }\end{array}$} & $\begin{array}{l}\text { Oportunidades de crescimento e aperfeiçoamento profissional } \\
\text { oferecidos pela empresa }\end{array}$ \\
\hline & Nível de conhecimento / habilidade para realizar as tarefas \\
\hline & Grau de motivação e ânimo ao chegar para trabalhar \\
\hline \multirow{3}{*}{ Remuneração e benefícios } & Remuneração em relação ao trabalho realizado \\
\hline & Benefícios de saúde oferecidos pela empresa aos trabalhadores \\
\hline & $\begin{array}{l}\text { Oportunidades de lazer e congraçamento entre trabalhadores e } \\
\text { familiares }\end{array}$ \\
\hline \multirow{3}{*}{ Relevância social do trabalho } & Imagem da empresa perante a sociedade \\
\hline & Relevância do trabalho para a empresa e a sociedade \\
\hline & Nível de equilíbrio entre a vida profissional e pessoal/familiar \\
\hline
\end{tabular}




\section{Resultados e discussão}

Na Tabela 1, são apresentados os valores da estatística Kappa para cada componente, seus respectivos intervalos de confiança e a porcentagem de concordância das respostas nas duas aplicações.

Todos os componentes apresentam níveis de concordância "substancial”, com exceção do componente "relevância social do trabalho”, que apresenta nível "moderado".

Na análise geral, envolvendo todos os componentes, encontrou-se um coeficiente de Kappa de 0,63 (IC95\%: 0,60; 0,66), representando 77,6\% de concordância das respostas entre o teste e o reteste (valor "substancial").
Nesta amostra, apenas o "grau de escolaridade" mostrou-se discriminante no grau de reprodutibilidade da escala, sendo o coeficiente de Kappa menor para os trabalhadores que possuem apenas o Ensino Fundamental (Tabela 2). Isto indica a menor validade da escala para trabalhadores com menor grau de escolaridade, principalmente para os componentes "ambiente social" e "relevância social do trabalho".

Os resultados obtidos das medidas de reprodutibilidade apresentam-se satisfatórios em geral e para quatro dos cinco componentes da escala.

Em síntese, este instrumento representa uma boa opção para o levantamento de informações sobre fatores relacionados ao perfil do ambiente e às condições de trabalho, podendo ser empregado com respondentes que possuam escolaridade maior que o Ensino Fundamental.

Tabela 1 Índice de concordância Kappa e concordância relativa com relação à cada componente da escala

\begin{tabular}{lccc}
\hline \multicolumn{1}{c}{ Componente } & Kappa & IC 95\% & Concordância \\
\hline Ambiente físico & 0,60 & 0,$53 ; 0,67$ & $74,9 \%$ \\
Ambiente social & 0,61 & 0,$53 ; 0,68$ & $77,3 \%$ \\
Desenvolvimento e realização profissional & 0,63 & 0,$56 ; 0,70$ & $78,4 \%$ \\
Remuneração e benefícios & 0,72 & 0,$66 ; 0,78$ & $81,8 \%$ \\
Relevância social do trabalho & 0,55 & 0,$47 ; 0,63$ & $75,5 \%$ \\
\hline Geral & 0,63 & 0,$60 ; 0,66$ & $77,6 \%$ \\
\hline
\end{tabular}

Tabela 2 Índice de concordância Kappa e intervalos de confiança (95\%) para cada componente, segundo o grau de escolaridade

\begin{tabular}{lcccc}
\hline \multicolumn{1}{c}{ Componente } & \multicolumn{2}{c}{ Grau de escolaridade } \\
& Fundamental & Médio & Superior & Pós-graduação \\
\hline \multirow{2}{*}{ Ambiente físico } & 0,40 & 0,60 & 0,62 & 0,62 \\
& $(0,17 ; 0,63)$ & $(0,48 ; 0,73)$ & $(0,50 ; 0,73)$ & $(0,44 ; 0,80)$ \\
Ambiente social & 0,32 & 0,59 & 0,65 & 0,62 \\
& $(0,08 ; 0,57)$ & $(0,46 ; 0,72)$ & $(0,53 ; 0,77)$ & $(0,45 ; 0,79)$ \\
Desenvolvimento e realização & 0,49 & 0,64 & 0,64 & 0,57 \\
profissional & $(0,27 ; 0,71)$ & $(0,52 ; 0,77)$ & $(0,52 ; 0,77)$ & $(0,40 ; 0,75)$ \\
& 0,41 & 0,76 & 0,76 & 0,73 \\
Remuneração e benefícios & $(0,18 ; 0,63)$ & $(0,65 ; 0,86)$ & $(0,66 ; 0,86)$ & $(0,58 ; 0,87)$ \\
& 0,33 & 0,53 & 0,63 & 0,66 \\
Relevância social do trabalho & $(0,10 ; 0,56)$ & $(0,38 ; 0,67)$ & $(0,50 ; 0,76)$ & $(0,48 ; 0,83)$ \\
\hline
\end{tabular}




\section{Referências}

ASSUNÇÃO, A. A. Uma contribuição ao debate sobre as relações saúde e trabalho. Ciência \& Saúde Coletiva, Rio de Janeiro, v. 8, n. 4, p. 1011-1026, 2003.

BARROS, M. V. G.; NAHAS, M. V. Reprodutibilidade (teste-reteste) do questionário internacional de atividade física - versão 6: um estudo piloto com adultos no Brasil. Revista Brasileira de Ciência e Movimento, Brasília, v. 8, n. 1, p. 23-26, 2000.

BOTH, J. et al. Validação da escala "perfil do estilo de vida individual”. Revista Brasileira de Atividade Física e Saúde, Pelotas, v. 13, n. 1, p. 5-14, 2008.

KERN, F. A. Qualidade de vida do trabalhador: o desafio da construção de índices. Porto Alegre: SESI, PUCRS, 1997. Relatório de pesquisa.

LANDIS, J. R.; KOCH, G. G. The measurement of observer agreement for categorical data. Biometrics, United States, v. 33, n. 1, p. 159-174, 1997.

METZNER, R. J.; FISCHER, F. M. Fadiga e capacidade para o trabalho em turnos fixos de doze horas. Revista de Saúde Pública, São Paulo, v. 35, n. 6, p. 548-553, dez. 2001.

NAHAS, M. V. Atividade física, saúde e qualidade de vida: conceitos e sugestões para um estilo de vida ativo. 4. ed. Londrina: Midiograf, 2006.
NAHAS, M. V.; BARROS, M. V. G.; FRANCALACCI, V. L. O pentáculo do bem-estar: base conceitual para avaliação do estilo de vida dos indivíduos ou grupos. Revista Brasileira de Atividade Física e Saúde, Pelotas, v. 5, n. 2, p. 48-59, 2000.

PEREIRA, S. V. Contribuição do programa de ginástica na empresa (SESI-SC) na mudança do estilo de vida dos participantes e na melhoria das relações interpessoais nas organizações. 2001. 97 f. Dissertação (Mestrado em Engenharia de Produção)-Universidade Federal de Santa Catarina, Florianópolis, 2001.

SUCESSO, E. P. B. Trabalho e qualidade de vida. Rio de Janeiro: Qualitymark, Dunya, 1998.

THOMAS, J. R.; NELSON, J. K. Métodos de pesquisa em atividade física. 3. ed. Porto Alegre: Artmed, 2002.

VASCONCELOS, A. F. Qualidade de vida no trabalho: origem, evolução e perspectivas. Caderno de Pesquisas em Administração, São Paulo, v. 8, n. 1, p. 23-35, jan./mar. 2001.

VILARTA, R.; GONÇALVES, A. Qualidade de vida e o mundo do trabalho. In: GONÇALVES, A.; VILARTA, R. (Org.). Qualidade de vida e atividade física: explorando teoria e prática. Barueri: Manole, 2004. p. 103-139. 